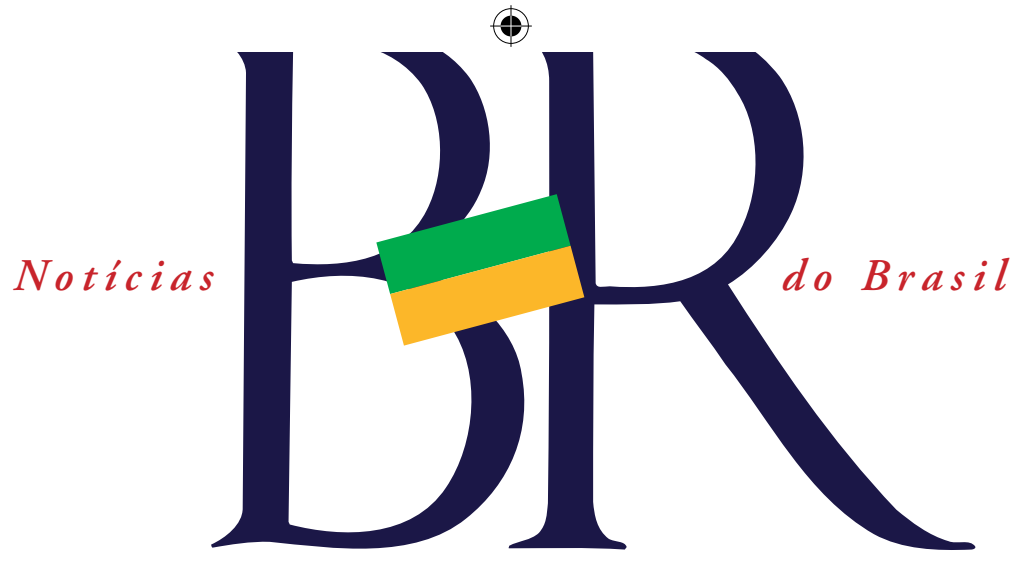

Entrevista Anna Cipparonne

\section{Preservação do patrimônio passa pela educação}

Ao idealizar e coordenar a criação do Sistema Museal da Província de Cosenza, Anna Cipparrone, historiadora da arte e especialista em gestão e marketing de turismo cultural perseguiu os seguintes objetivos: potencializar a ação didática dos museus e dos acervos disponíveis, difundir o turismo artístico-cultural na região e melhorar a estrutura física e de pessoal dessa região ao sul da Itália, na Calábria. Como diretora da Instituiçãa do Museu de Arte e dei Mestieri (MAM) della Provincia di Cosenza, sua principal motivação foi alimentar o interesse dos cidadãos com relação aos bens culturais do lugar onde vivem.
O que é a rede virtual de museus de Cosenza?

A Rede Museal da Província de Cosenza (www.retemuseale.provincia.cs.it) é o primeiro passo de um projeto mais amplo e ambicioso do Sistema Museal Municipal e se configura como um portal na internet no qual todos os museus da região, além do patrimônio arqueológico, arquitetônico e artístico, são descritos minuciosamente e abertos a visitantes virtuais. Trata-se de um projeto inovador que nenhuma outra cidade da Calábria realizou até agora e que pretende ser um modelo para esta região do sul da Itália. O desejo é que outras localidades possam criar seu próprio sistema, formando uma rede mais ampla para difundir de maneira única e homogênea toda a excelência de seus atrativos culturais ao exterior. Mostrar regiōes como Bronzi di Riace a Reggio Calabria, Mattia Preti e Taverna, entre outros, com tesouros arqueológicos de diferentes origens e as cerca de 300 torres e castelos, memórias do domínio normando-sueco, do período da dinastia dos Bourbons e tantos outros marcos é fundamental para manter viva uma história tão rica. Um sistema assim construído pretende não perder nem esquecer os bens existentes nessas regiōes e promover o patrimônio cultural do território de modo científico e sistemático.

\section{Quanto tempo levou para levantar} todo o acervo e qual a interatividade que dispõe?

O estudo do patrimônio cultural e, sobretudo, o censo dos museus da província de Cosenza - cerca de 100 pequenos e grandes museus - começou em 2008 e, depois de dois anos de visita a todos os locais do território cosentino, 155 cidades, a pesquisa bibliográfica e a compilação de todas as informa-

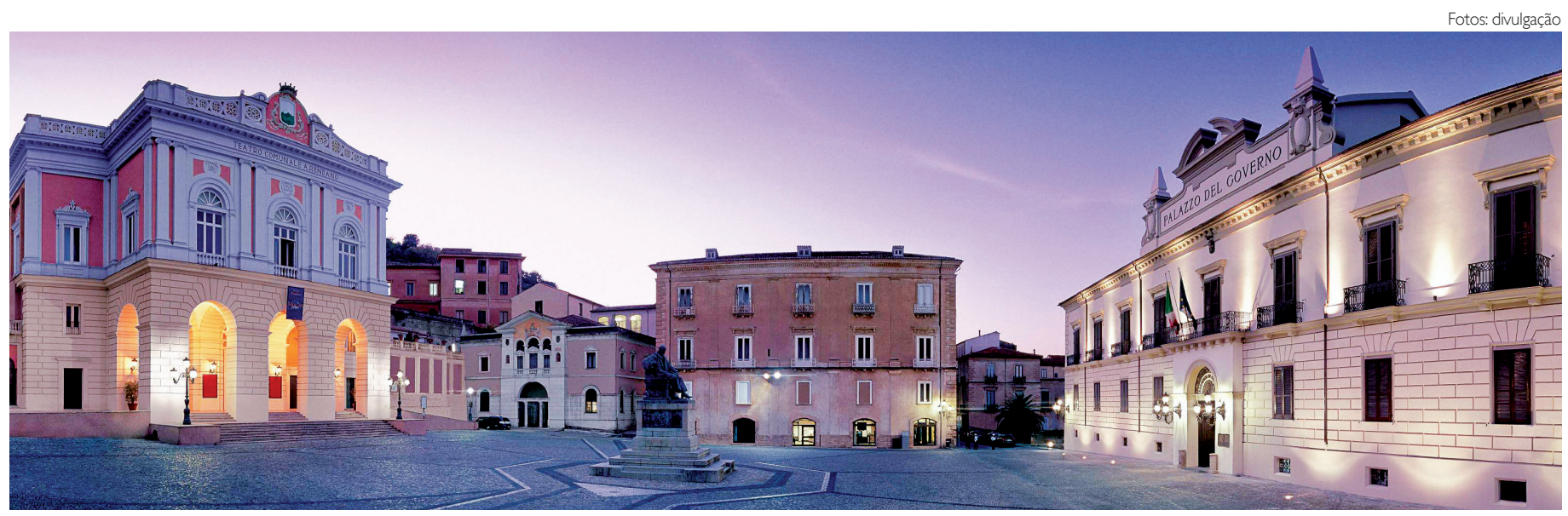

Cosenza: Piazza XV de Março, Palácio da Província, teatro Rondano e monumento a Bernardino Telesio 


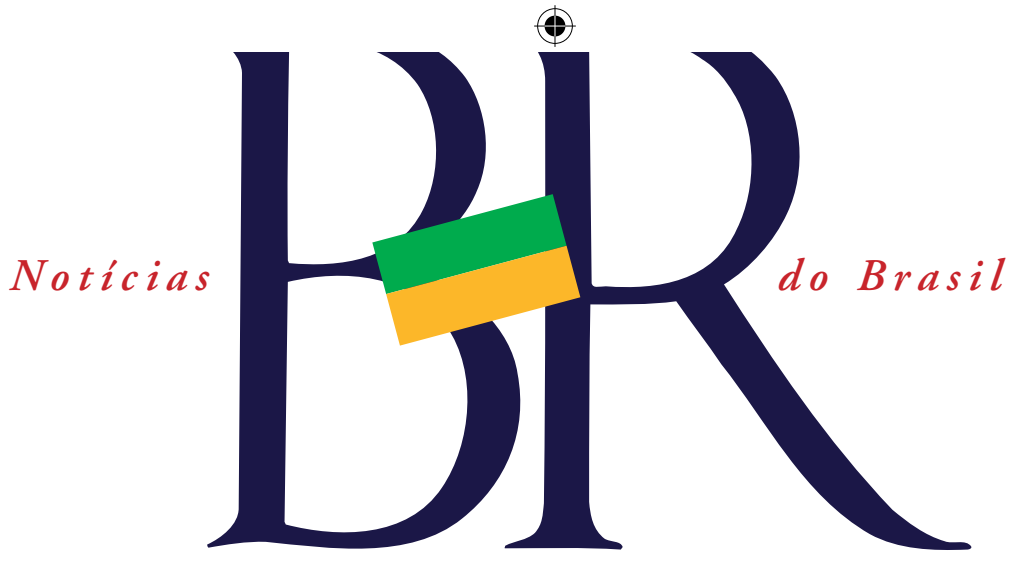

ções conduziram à publicação on line da rede museal, em fevereiro de 2011. A Calábria é o berço da civilização ocidental e abrigou a maior colônia grega. Dispõe, portanto, de enorme acervo arqueológico, de objetos da antiga civilização camponesa, obras de arte sacra (prataria, tecidos, pintura e esculturas), símbolos da produção alimentícia local (museu do cedro, do vinho, do óleo, do pão, do aniz/liquirizia, da pimenta, entre outros), museus naturais, museus históricos (desde aqueles dedicados à cavalaria dos Bourbons ou ao campo de concentração de Ferramont) e, enfim, museus étnicos. Estes, de fundamental importância para definir a variedade e a estratificação cultural do território cosentino, incluem vestimentas, documentos, usos e tradições das etnias albanesa e valdesa que existem em 23 cidades da região e que, embora sendo perfeitamente integradas, mantêm vivas e respeitam profundamente suas raízes.

É possível acessar essas coleções seja fisicamente, indo às cidades, ou navegando pela Rede Museal (www. retemuseale.provincia.cs.it)

Quais os objetivos que moveram seu trabalho frente ao patrimônio cultural de sua região?

Além da publicação on line que viabiliza uma difusão capilar do patrimônio na web, o objetivo é levar o

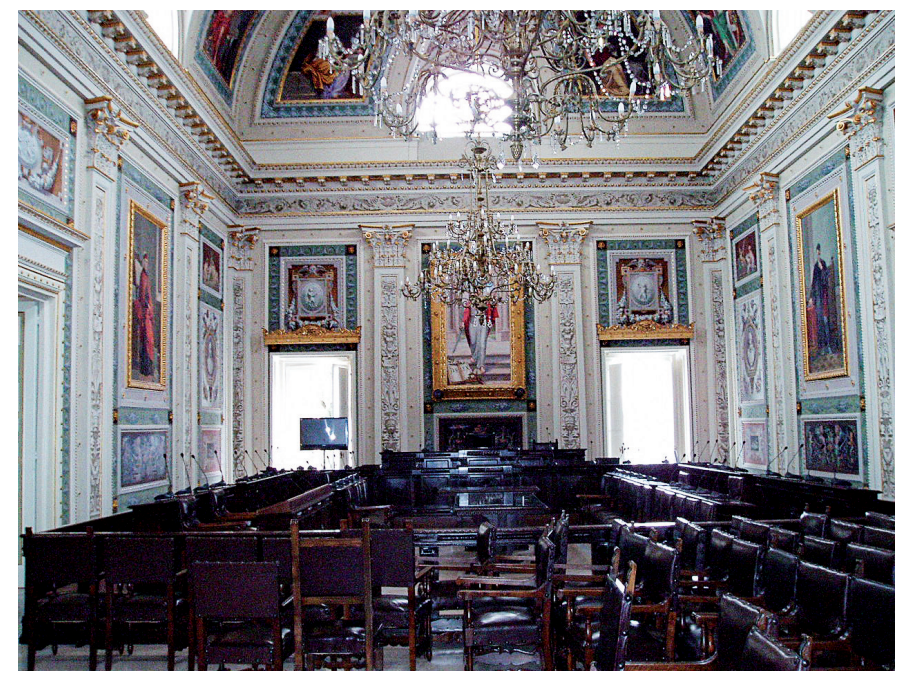

Salão do Conselho Provincial em Cosenza, pintado em 1881 pelo florentino Enrico Andreotti com ajuda de jovens artistas locais

conhecimento das especificidades históricas e artísticas de seu território, para que as pessoas se conscientizem de que na Calábria, assim como em toda a Itália, o conceito de bem cultural não pode prescindir da vivência de cada um. Hoje são registradas dispersões, perdas e depauperamentos dos bens culturais. A sociedade é responsável por esses anos de desatenção e também por falta de fundos destinados à cultura. Somente com a conscientização de que o bem cultural é parte integrante da nossa existência será possível deter esse declínio e transmitir ao exterior uma imagem mais forte e unitária da província, da região e da nação como um todo.

Graças ao conhecimento e ao estudo é possível favorecer a manutenção e o respeito ao patrimônio cultural e, com isso, contribuir para a tutela e para a conservação dos tes- temunhos históricos de nosso rico e glorioso passado.

Nessa direção se move a fase didática do projeto, que envolve todas as escolas do território da província, com seminários em sala de aula sobre o conceito de bem cultural e de museu, sobre as características da fruição e sobre a importância do respeito e da manutenção do patrimônio. Num segundo momento, alunos e professores se registram em uma plataforma e-learning para baixar materiais e vídeo-aulas sobre museus da Rede Museal. Por fim, cada classe, que tenha aderido ao projeto, agenda um ou mais itinerários de visita aos museus do território da província com a finalidade de aprofundar uma temática escolhida ad hoc pelos professores com base nas atitudes dos jovens, de seus programas curriculares e desejos de conhecimento. Todas as viagens são cus- 
